\title{
Swiss Startup Framework: A Highly Effective Network Supporting the Generation of Emerging Biotech Businesses
}

\author{
Isabelle Mitchell (Venture Kick), Stefan Steiner (Venture Leaders), Michael Altorfer* (Swiss Biotech \\ Association), and Laura Suter-Dick (biotechnet Switzerland)
}

\begin{abstract}
For over 50 years, Switzerland has been one of the leading countries driving innovation in biotechnology and its industrial applications. Today, some 1,000 biotech companies form a tightly knit, cross-functional network ranging from research through to manufacturing ${ }^{[1]}$ This network comprises R\&D companies, contract research organizations, and highly specialized advisors and biotech investors. Together, they form an external innovation pool that complements the in-house R\&D capacity of the large multi-national pharma companies. A highly effective startup framework, solid acceleration mechanisms, and innovative investors enable the emergence of a continuous flow of biotech startups that revitalize the industry with new technologies and products supporting drug development and diagnostics.
\end{abstract}

Keywords: Biotechnology $\cdot$ Financing $\cdot$ Innovation $\cdot$ Startup $\cdot$ Therapeutics

Diverse sources of innovation can lead to the formation of new biotech startups. Some of the new companies are formed as spin-offs from leading universities or multi-national pharma companies. Others are founded by senior industry specialists or biotech investors. In addition, biotech companies founded in other countries regularly transfer to Switzerland, where they can take advantage of the startup-friendly framework conditions. The sweeping tax reform of 2020 is just the latest example of the ways in which Switzerland encourages R\&D investments and provides tax exemptions for those revenues generated from innovations made in Switzerland.

The formation of new biotech startups is a function of four fundamentals underpinning the translation of research into commercial value: scientific research output, biomedical patent activity, presence of VCs (Venture Capital) with an interest in the biomedical field, and the abundance of human capital flowing from top quality universities. Switzerland abounds in all four of these areas and was ranked as number one of 16 European countries analyzed on a per capita basis, in Nature Biotechnology's fiveyear comparative assessment in 2019. [2]

Many of the emerging biotech companies set out to transform innovation into value-generating industrial applications, and to develop new drugs and therapeutic options that address pressing medical needs. A host of partners stand ready to support these startups: to help them attract the best talents in the field, obtain sufficient financing, and to provide access to the relevant stakeholders in the Swiss biotech ecosystem which can further the startups' development. The overarching goal is to ensure that newcomers are visible from the very start and able to effectively join the powerful Swiss biotech ecosphere. In 2019, the Swiss biotech companies attracted CHF 1.2 billion new investments and invested more than CHF 2 billion into their R\&D programs. ${ }^{[3]}$

\section{1. biotechnet Switzerland Facilitates Collaborations between Academic Research Groups and the Biotech Industry}

Switzerland has been facilitating technology transfer from academic research groups to industrial partners for decades. For the most part, support from the Swiss government is provided through private-public partnerships. Innosuisse, the Swiss innovation agency, provides funds to academic research groups that apply their know-how and expertise in joint projects with industrial partners. Similarly, academic research and industrial biotech companies can partner in European projects funded by European innovation programs, such as the Horizon 2020 program or Eurostars.

These private-public partnerships have an excellent track record when it comes to helping startups to effectively transfer innovative technologies and research findings developed by universities to industrial applications. For many years, the two organizations - biotechnet Switzerland and the Swiss Biotech Association - have facilitated and encouraged private-public partnerships and supported them through the joint NTN (National Thematic Network) Swiss Biotech activities.

\begin{tabular}{|l|l|}
$\begin{array}{l}\text { biotechnet } \\
\text { Switzerland }\end{array}$ & \\
\hline Key Figures & 1998 \\
\hline Founding Year & Muttenz \\
\hline Location(s) & Association \\
\hline Legal Form & \\
\hline Contact & Prof. Dr. Laura Suter-Dick, President \\
\hline Contact Person &
\end{tabular}




\begin{tabular}{|l|l|}
\hline Address & $\begin{array}{l}\text { c/o FHNW, Hofackerstrasse 30 } \\
\text { 4132 Muttenz }\end{array}$ \\
\hline Email & laura.suterdick@fhnw.ch \\
\hline Website & www.biotechnet.ch \\
\hline
\end{tabular}

biotechnet Switzerland provides a network of academic partners that offers access to a broad spectrum of high-level competences in biotechnology at Swiss universities and research and technology organizations.

\section{The Leverage Effect of Venture Kick's Early-stage Financing}

Venture Kick provides Swiss university spin-offs with preseed capital, coaching, and access to professional investors. The initiative aims to build an entrepreneurial framework that transforms scientific innovation into commercial activity strengthening the foundation of social and economic prosperity. By supporting early-stage startups, which tend to be high risk and therefore not covered by public money or private investors, Venture Kick fills a crucial gap and performs a philanthropic role in society. Venture Kick's nine-month kick-start process supports young entrepreneurs with high-potential business ideas on their journey from the science laboratory to global markets. Each month, a Venture Kick jury, drawn from a pool of more than 160 startup experts in Switzerland, evaluates about 16 startup projects over three separate jury sessions.

The multi-faceted support offered by Venture Kick has a demonstrable impact and generates huge leverage. Between 2007 and 2019, Venture Kick supported 81 startups in the biotech sector with CHF 3,900,000 of funding. These startups have received follow-up financing of CHF 1.05 billion, which means that for every Swiss Franc of pre-seed money invested by Venture Kick, some CHF 270 was invested by others (Fig. 1). Of the 81 biotech startups that were supported between 2007 and 2019, 59 are still active (56 operate as independent companies and 3 have been acquired) and have created around 600 jobs.

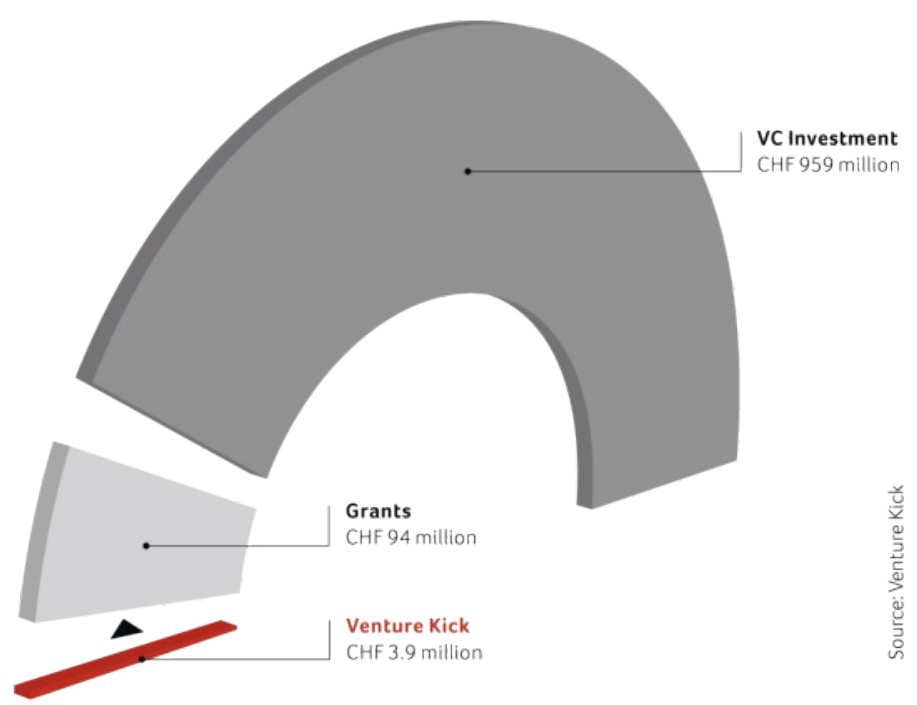

Fig. 1. Leverage effect of Venture Kick's early-stage financing in 81 biotech startups over a period of 13 years

\section{Venture Kick}

\section{VENTURE:}

\begin{tabular}{|l|l|}
\hline Key Figures & \\
\hline Founding Year & 2007 \\
\hline Location(s) & Schlieren, Lausanne \\
\hline Legal Form & Foundation \\
\hline
\end{tabular}

\section{Contact}

Contact Person

Beat Schillig, Co-Managing Director

Address

Venture Kick

c/o Venturelab Ltd, startup space

Wiesenstrasse 5, 8952 Schlieren

Email

Website info@venturekick.ch

www.venturekick.ch

\section{Venture Leaders: Connecting Swiss Life Sciences Startups with the World}

Since 2005, the Swiss startup support organization, Venturelab has selected Swiss National Startup Teams made up of entrepreneurs with global ambitions. Members of these teams, called Venture Leaders, are given the opportunity to explore international entrepreneurial hubs and meet with stakeholders and investors. Hubs visited include Boston, Silicon Valley, New York, Barcelona, Beijing, Shanghai, Shenzhen, and Hong Kong. As of April 2020, the companies founded by the 415 Venture Leaders, who have been through this program, have created more than 3,500 jobs and raised more than CHF 1.7 billion in capital.

Each year, a jury of investors and industry experts selects 10 promising Swiss life sciences startups to represent Switzerland on the Venture Leaders Life Sciences roadshow to Boston. There, the Venture Leaders pitch to key US investors and meet leaders and experts in the biotech and medtech industries. The Venture Leaders startup development program is specifically structured to support the life sciences entrepreneurs with a solid network, critical market exposure, relevant feedback from investors and experts, and hands-on business development.

\section{Venture Leaders \\ Life Sciences}

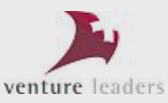

\section{Key Figures}

Founding Year 2005

Location(s)

Schlieren, Lausanne

Contact

Contact Person

Jordi Montserrat, Managing Partner of Venturelab

\begin{tabular}{l|l} 
Address & Venture Leaders
\end{tabular} c/o Venturelab Ltd, startup space Wiesenstrasse 5, 8952 Schlieren

Email jordi.montserrat@venturelab.ch

Website www.venture-leaders.ch/lifesciences 
The Venture Leaders Life Sciences alumni have raised CHF 647 million in equity capital. The alumni include high-flying startups such as Covagen (acquired by Johnson \& Johnson), Redbiotec (partly acquired by Pfizer), KB Medical (acquired by Globus Medical), SimplicityBio (acquired by Precision for Medicine), and AMAL Therapeutics (acquired by Boehringer Ingelheim).

\section{Swiss Biotech Association: Connecting Biotech Startups in the Swiss Ecosystem}

When a new biotech startup is founded, the Swiss Biotech Association invites the company to list itself in the Swiss Biotech Directory at www.swissbiotech.org/companies. This directory serves as a promotion platform aimed at the Swiss biotech hub and international partners. It also provides vital insights into the Swiss biotech industry for international investors, pharma scouting, CROs, and international talents.

At the Swiss Biotech Day, startups are invited to present themselves to industry stakeholders. As a member of the Swiss Biotech Association, the emerging companies can also publish open positions, news, and key events through the Swiss Biotech website. The association's newsletter, biotech insight meetings, Swiss Biotech Association academy events, and other information channels help startups to be well informed and well connected within Switzerland.

Internationally, the Swiss Biotech Association and Switzerland Global Enterprise organize the Swiss pavilion at the key partnering conferences Bio US and Bio Europe and offer startups an effective platform to increase their international visibility as part of the Swiss biotech hub.

\begin{tabular}{|l|l|}
$\begin{array}{l}\text { Swiss Biotech } \\
\text { Association }\end{array}$ & \\
\hline Key Figures & 1998 \\
\hline Founding Year & Zurich, Lausanne \\
\hline Location(s) & Association \\
\hline Legal Form & \begin{tabular}{l} 
Missociation \\
\hline Contact
\end{tabular} \\
\hline Contact Person & Marta Gehring, Liaison Romandie \\
\hline Address & $\begin{array}{l}\text { Stauffacherstrasse 16, 8004 Zürich } \\
\text { Avenue d'Ouchy 47, 1006 Lausanne }\end{array}$ \\
\hline Email & info@swissbiotech.org \\
\hline Website & www.swissbiotech.org \\
\hline
\end{tabular}

The Swiss government does not typically support direct investments into biotech startups but the combined effort of foundations, university technology transfer offices, and organizations like Innosuisse does facilitate their creation and funding. Biotechnet Switzerland and the Swiss Biotech Association support the integration of startups into the Swiss biotech industry and, through a network of larger associations, also provide them with an effective network in Switzerland (Interpharma, ${ }^{[4]}$ scienceindustries, ${ }^{[5]}$ economiesuisse ${ }^{[6]}$ ) and internationally through EuropaBio, ${ }^{[7]}$ and the International Council of Biotech Associations (ICBA). ${ }^{[8]}$

Received: July 4, 2020

[1] Swiss Biotech Directory: www.swissbiotech.org/companies

[2] 'Mapping the European startup landscape', Bioentrepreneur, Nature Biotechnol. 2019, 37, 345

[3] www.swissbiotechreport.ch, 2020.

[4] www.interpharma.ch

[5] www.scienceindustries.ch

[6] http://www.economiesuisse.ch/

[7] www.europabio.org

[8] www.internationalbiotech.org

\section{License and Terms}

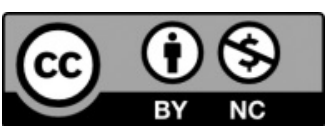

This is an Open Access article under the terms of the Creative Commons Attribution License CC BY_NC 4.0. The material may not be used for commercial purposes.

The license is subject to the CHIMIA terms and conditions: (http:// chimia.ch/component/sppagebuilder/?view=page \&id=12).

The definitive version of this article is the electronic one that can be found at https://doi.org:10.2533/chimia.2020.765 